\title{
Cintra Torres, Eduardo (2006), A Tragédia Televisiva: um género dramático da informação audiovisual, Lisboa: ICS.
}

Felisbela Lopes*

Se o autor desta obra quisesse selar promessas de leitura com aquele que percorre as páginas do seu livro, as propostas poderiam ser diversas. O leitor poderia procurar elementos que o ajudassem a perceber, por um lado, a ligação que a TV mantém com o real e, por outro, a relação que o espectador constrói com a realidade mediatizada pelo pequeno ecrã; poderia igualmente ir em busca das novas configurações que o jornalismo televisivo tem vindo a adquirir e de renovadas posturas que os jornalistas vêm exibindo no trabalho que desenvolvem; poderia também entrar pelo meio de uma teoria dos géneros e indagar aí as razões que fundamentam a "tragédia televisiva" como um género autónomo; ou poderia, simplesmente, percorrer as três centenas de páginas desta obra acompanhando uma original e pertinente análise à mediatização audiovisual de dois acontecimentos que, às escalas nacional e internacional, marcaram o nosso passado recente: a queda da Ponte Hintze Ribeiro sobre o Douro em Março de 2001 e o ataque às Torres Gémeas e ao Pentágono que ocorreu a 11 de Setembro. Saliente-se ainda que este trabalho, escrito com grande apuramento de linguagem, está carregado de um grande número de referências bibliográficas que cruzam áreas disciplinares diversas e atravessam tempos díspares, expostas de forma tão fluida que se pensa ser o mais natural possível falar da televisão contemporânea à luz dos escritos de Aristóteles, de Goethe ou de Almeida Garrett. "Ir à procura da tragédia no fundo dos tempos. E no fundo do ecrã. E no espectador", escreve-se logo na segunda página. Percorrida toda a obra, poder-se-á assegurar que o autor trilhou, laboriosamente, todo o percurso que prometera fazer.

O mote deste trabalho - que correspondeu à tese de mestrado que Eduardo Cintra Torres defendeu no ISCTE - foi a análise da cobertura televisiva feita pelos canais portugueses à queda da Ponte de Entre-os-Rios e pelas estações norte-americanas ao 11 de Setembro, bem como o estudo da relação que os telespectadores criaram com esses acontecimentos através daquilo que viram na TV. Esta última parte foi construída com base num inquérito de conveniência junto de cerca de 1300 espectadores, usando-se ainda elementos recolhidos num estudo qualitativo com espectadores (grupo foco). São várias as interrogações que se constituíram como pontos de partida (p. 19). Citam-se aqui apenas duas:

- Por que razão se chama "tragédias" a certo tipo de eventos catastróficos ou de ruptura?

* Professora de Jornalismo na Universidade do Minho e Investigadora do Centro de Estudos de Comunicação e Sociedade da mesma universidade (felisbela@ics.uminho.pt). 
- Haverá semelhanças entre as emissões televisivas dessas "tragédias” e a tragédia clássica?

Talvez a linguagem de senso comum possa confundir "tragédia televisiva", "acontecimento mediático" ("media event" no sentido que lhe deram Dayan e Katz) e “melodrama informativo". Para quem lê a obra será difícil a confusão, até porque Cintra Torres se detém com pormenor nos traços distintivos destes três conceitos que considera "géneros" (pp. 103-109). Mais à frente, o ponto consagrado às "personagens da tragédia televisiva" (pp. 135-166) apresenta esses diferentes actores e o modo como ocupam a cena mediática que o pequeno ecrã configura.

Fazendo acompanhar a análise empírica feita à cobertura televisiva de uma ampla e diversificada reflexão teórica, Eduardo Cintra Torres cria oito pontos que poderiam constituir-se como capítulos, se assim tivessem sido enunciados. A abrir o primeiro ponto que intitula "Os acontecimentos trágicos no mundo contemporâneo e o papel atribuído à televisão”, o autor fixa o seu entendimento de tragédia televisiva:

“conjunto das transmissões pela televisão generalista de um evento de âmbito nacional ou internacional de carácter inesperado, altamente improvável, provocando ruptura na ordem social ou política, envolvendo a morte violenta de uma celebridade política, mediática ou de muitas pessoas desconhecidas em resultado de um atentado, ataque terrorista, acidente ou catástrofe natural, evento esse que origina e interage com uma transmissão televisiva jornalística em directo que interrompe o normal fluxo televisivo, gera uma importante atenção pública, prolonga-se por um período de vários dias e adquire características semelhantes à tragédia como texto e espectáculo" (p. 23).

Nas páginas que estão pela frente, haverá a oportunidade para dissecar cada um destes vectores. Como o tratamento jornalístico da morte, nomeadamente dos casos em que há um grande número de cadáveres por encontrar, como aconteceu nos casos da queda da Ponte de Entre-os-Rios e no 11 de Setembro (pp. 111-134). Cintra Torres reactualiza algumas passagens de Antígona para lembrar que também na obra de Sófocles a mola da acção era o destino a dar ao cadáver do irmão da protagonista e também aí o problema dos mortos se assumiu como uma questão que envolvia o poder (p. 113). Entre a literatura e a realidade, não parece haver diferenças. Entre o passado longínquo e o presente, não se vislumbram evoluções significativas. Não é a primeira vez que somos colocados perante esse tipo de proximidade.

Num ponto dedicado ao directo televisivo ("uma das principais características da tragédia televisiva”, p. 47), Eduardo Cintra Torres cita a Poética de Aristóteles para recordar que “a representação dramática é 'ao vivo', tal como o directo televisivo" (p. 55). Nesta parte, assinalam-se episódios peculiares das transmissões televisivas dos acontecimentos em estudo: "no final de uma jornada informativa em que a RTP1 esteve no ar cerca de nove horas em directo de Castelo de Paiva, o apresentador do noticiário da noite definiu esse tempo como 'um dia em que praticamente nada se passou nas margens do Douro"” (p. 59). Nestes casos, o espectador parece importar-se pouco com uma informação de grau zero, porque a sua curiosidade mantém-se des- 
perta em relação àquilo que ali (não) se passa. Sublinhe-se, a este respeito, o aumento do consumo televisivo registado durante a cobertura da queda da Ponte de Entre-os-Rios e os atentados do 11 de Setembro (p. 226), bem como a preferência que as pessoas manifestaram relativamente às transmissões em directo (p. 228).

A instância de recepção é, aliás, um dos vectores a que este trabalho dá particular importância. Para analisar o modo como os telespectadores se relaciona(ra)m com os acontecimentos em estudo, nomeadamente as emoções experimentadas, promoveu-se um inquérito de conveniência. Os resultados são apresentados com assinalável grau de pormenor nos pontos intitulados “a dimensão emocional da tragédia televisiva” (pp. 167-204) e “o espectador individual e colectivo da tragédia televisiva” (pp. 205-252). Destacamos alguns desses dados.

No que diz respeito às emoções dos telespectadores, o horror e a pena reuniram um alto índice de expressão (p. 208). Cintra Torres nota assertivamente que Aristóteles havia já apontado como objectivo do texto e da representação trágica o terror e a piedade, emoções análogas àquelas que manifestaram os inquiridos, quando solicitados a recordar as tragédias televisivas em estudo (p. 178). Umas páginas à frente, cita-se Luc Boltanski para referir a piedade de que fala Aristóteles e que o autor do livro La Souffrance à distance aplica ao (tel)espectador (p. 188). Olhado o sofrimento dos outros através da televisão, a maior parte dos inquiridos neste trabalho percepciona aquilo que vê como uma tragédia em que poderia também estar envolvido (p. 235). Quanto à qualidade do jornalismo desenvolvido pelos canais de televisão aquando destes dois acontecimentos, os dados revelam percepções que podem provocar algum espanto. Tendo sido acusados de sensacionalismo e de avanços significativos na exploração gratuita da dor dos familiares das vítimas, os jornalistas são elogiados pelo seu trabalho que, segundo os inquiridos de Cintra Torres, não terá ultrapassado os limites do aceitável (p. 239). À pergunta se os jornalistas devem mostrar as suas emoções, $33,3 \%$ recusaram tal comportamento, 33\% mostraram-se indiferentes e 33,7\% aceitam essa postura como normal (p. 240).

Nas emissões televisivas analisadas, encontram-se tiradas de jornalistas que se preocupam em explicar que a emoção que manifestam era impossível de ocultar. Andrea Neves, jornalista da RTP destacada para Entre-os-Rios aquando da queda da ponte, afirma num dos directos isto: “é impossível que qualquer jornalista português que esteja a acompanhar em permanência o que está acontecer não deixe de pensar e não deixe também de sentir, porque esta é uma tragédia que nos atinge a todos" (p. 269). Dan Rather, o "anchor" da CBS, chorou na primeira emissão do programa de David Lettermann após o 11 de Setembro. Referindo esse episódio num artigo intitulado "Let reporters show emotion" - citado neste livro - a sua autora, a jornalista Jessica Hodgson, cita o presidente da CNN, Chris Cramer, que afirma o seguinte: "como patrões, se não permitimos ao nosso pessoal a capacidade de demonstrar emoção não somos bons chefes” (p. 269).

Também a literatura confirma a impossibilidade de se fazer a subtracção de determinadas emoções. No entanto, a inclusão de marcas emotivas no discurso jornalístico 
terá tanto de imprescindibilidade como de risco. "Sem suscitar emoções, a tragédia não faria sentido na relação com o espectador, o mesmo acontecendo na representação jornalística de factos reais trágicos na televisão", escreve Cintra Torres, logo depois de citar Aristóteles (p. 267). Segue-se, de imediato, uma outra citação de Boltanski, segundo o qual, perante o sofrimento, "a descrição pura e simples, factual, que se daria por objectivo dizer as coisas como elas são, tal e qual (...) é uma possibilidade excluída”. Isto implica um outro modo de pensar o discurso jornalístico e a postura profissional dos jornalistas. Poderiam estas questões circunscreverem-se a pontuais e excepcionais situações, não se desse o caso de o jornalismo, particularmente o televisivo, estar em mudança, incorporando cada vez mais acontecimentos estruturados pela emoção, muito próximos da tragédia: “o desenvolvimento da atenção aos desastres, guerras e catástrofes naturais levou essa bolha informativa a rebentar, tomando conta do fluxo televisivo" (pp. 262-263), escreve-se num ponto dedicado precisamente às mudanças por que passa actualmente o jornalismo. Essa inclinação caminha em paralelo com uma contemporaneidade em que o emotivo se assume como uma espécie de “cola de mundo" e com uma (neo)televisão que cultiva um jornalismo de afectos. "A televisão cria a tragédia. Ela faz do evento trágico do mundo real uma reality tragédia de realidade, um género esquivo que marca a vida dos cidadãos e dos telespectadores" (p. 303). Este movimento circular - que é reafirmado no fecho desta obra - remete-nos para a urgência de repensar permanentemente a informação televisiva. A este nível, talvez faça sentido desenvolver uma reflexão apurada em torno de uma ecologia das palavras e das imagens que o jornalismo se permite apresentar. Este livro constituir-se-á sempre como um imprescindível ponto de partida nesse trabalho. 